\title{
Predictions of elemental composition of coal and biomass from their proximate analyses using ANFIS, ANN and MLR
}

\author{
Abiodun Ismail Lawal ${ }^{1}$ - Adeyemi Emman Aladejare ${ }^{2} \cdot \operatorname{Moshood~Onifade~}^{3,4} \cdot$ \\ Samson Bada ${ }^{5}$ Musa Adebayo Idris 6
}

Received: 17 November 2019/Revised: 20 April 2020/Accepted: 2 July 2020/Published online: 15 July 2020

(C) The Author(s) 2020

\begin{abstract}
The elemental composition of coal and biomass provides significant parameters used in the design of almost all energy conversion systems and projects. The laboratory tests to determine the elemental composition of coal and biomass is time-consuming and costly. However, limited research has suggested that there is a correlation between parameters obtained from elemental and proximate analyses of these materials. In this study, some predictive models of the elemental composition of coal and biomass using soft computing and regression analyses have been developed. Thirty-one samples including parameters of elemental and proximate analyses were used during the analyses to develop multiple prediction models. Dependent variables for multiple prediction models were selected as carbon, hydrogen, and oxygen. Using volatile matter, fixed carbon, moisture and ash contents as independent variables, three different prediction models were developed for each dependent parameter using ANFIS, ANN, and MLR. In addition, a routine for selecting the best predictive model was suggested in the study. The reliability of the established models was tested by using various prediction performance indices and the models were found to be satisfactory. Therefore, the developed models can be used to determine the elemental composition of coal and biomass for practical purposes.
\end{abstract}

Keywords Biomass · Coal $\cdot$ Elemental composition $\cdot$ Proximate analysis $\cdot$ Soft computing $\cdot$ Regression analysis

\section{Introduction}

The world's energy demand has steadily increased owing to rising population and living standards (Chen et al. 2015). Due to this reason, fossil fuel reserves are ending slowly

Moshood Onifade

onifade.moshood@tdtu.edu.vn

Abiodun Ismail Lawal

ailawal@futa.edu.ng

Adeyemi Emman Aladejare

adeyemi.aladejare@oulu.fi

Samson Bada

samson.bada@wits.ac.za

Musa Adebayo Idris

idris.musa@ltu.se

1 Department of Mining Engineering, Federal University of Technology, Akure, Nigeria
(Mohr et al. 2015; Shafiee and Topal 2009). Coal is the major world energy single source, and it acts as the guarantor of energy security, supplying $38 \%$ of the whole world electricity (IEA 2018). Furthermore, it will still account for $26 \%$ of the world's electricity supply in 2040, as predicted by the International Energy Agency (2018).

2 Oulu Mining School, University of Oulu, Oulu, Finland

3 Informetrics Research Group, Ton Duc Thang University, Ho Chi Minh City, Vietnam

4 Faculty of Applied Sciences, Ton Duc Thang University, Ho Chi Minh City, Vietnam

5 Clean Coal and Sustainable Energy Research Group, Faculty of Engineering and the Built Environment, University of the Witwatersrand, Johannesburg, South Africa

6 Division of Mining and Geotechnical Engineering, Department of Civil, Environmental and Natural Resources Engineering, Luleå University of Technology, Luleå, Sweden 
The studies on renewable energy and alternative fuels around the world have been reported in the literature. Wood biomass has been acknowledged as a potential source of renewable energy because of its accessibility in most areas of the world (Van der stelt et al. 2011). Properties such as the high quantity of moisture, low bulk density, low calorific value and high energy requirements for grinding are the limitations of biomass that restrict its wider use for power generation (Haseli 2018). One of the main properties for the utilization of coal and biomass materials is the elemental composition (Chen et al. 2015). A special instrument is required to determine the elemental composition of coal, while data for proximate analysis can be readily acquired using common equipment (Shen et al. 2010)

The elemental composition of biomass is a significant asset that defines the amount of energy and evaluates the clean and efficient use of biomass materials (Chen et al. 2015). The elemental composition is a needed factor in evaluating the process of chemical conversion and predicting the flow of flue gas and the quality of air in coal combustion (Nhuchhen 2016). The proximate analysis is a fuel property that provides for the chemical composition of coal and confirms the appropriate usage of coal. Focusing on proximate and elemental analyses, a number of fuel parameters can be examined (Mathews et al. 2014).

The characteristics of coal and biomass are necessary for the production of their potential and also the effective operation of the energy conversion process. In the past, several relationships have been established using ultimate and proximate analyses. Chelgani et al. (2008) established a technique to predict the grindability of coal by multiple regression and artificial neural network (ANN) models from the data obtained from proximate and ultimate analyses. Furthermore, on the basis of the ultimate analysis of solid, fluid and gaseous fuels, the relationship to predict higher heating value was established by Channiwala and ParikhP (2002). Similarly, the heating value of biomass and municipal solid waste (MSW) was determined using the data obtained from proximate analysis (Parikh et al. 2007; Komilis et al. 2012). Previous studies have shown that no studies have established models to predict the elemental composition from the proximate analysis of coal and biomass materials except for the relationship developed by Vakkilainen (2000) particularly for black liquor only. Thus, the existing gap has necessitated the current study.

The design of energy conversion systems requires the elemental composition of coal, biomass and other related materials. Hitherto limited researches on correlations have been published to evaluate the elemental composition using proximate analysis of these materials. There has been a significant increase in recent research on biomass, coal and related materials, which requires an elemental analysis of these materials for the assessment of the complete process of any thermochemical conversion techniques. Therefore, this research aims to evaluate the elemental composition of both coal and biomass materials obtained from South Africa (SA) and Nigeria Coalfields from their proximate analysis using soft computing and regression analyses. The study makes use of ANN, adaptive neuro-fuzzy inference system (ANFIS) and multilinear regression (MLR) based on laboratory test results to eliminate the need for timeconsuming and costly elemental experimental analysis. Laboratory tests were conducted to examine the proximate analysis and elemental analysis of the coal and biomass materials. The results of the proximate analysis will be used as the input parameters in the proposed models and the elemental composition will be the targeted output. The predicted results of the ANFIS, ANN and MLR will be compared with the existing models and the model with the best fit/performance from the coefficient of determination, average absolute error, average biased error and mean the absolute error will be proposed for predicting the elemental composition of both coal and biomass materials.

\section{Experimental investigation}

To develop the models, proximate and elemental data relating to different coal samples and biomass (forest and agricultural wastes) were used to cover a wide range of values for fixed carbon (FC), moisture $(\mathrm{M})$, volatile matter $(\mathrm{VM})$, ash $(\mathrm{A})$, carbon $(\mathrm{C})$, hydrogen $(\mathrm{H})$, nitrogen $(\mathrm{N})$, oxygen $(\mathrm{O})$ and sulphur $(\mathrm{S})$ contents. A total of 31 samples (8 coal samples from Nigeria (NIG), 8 coal samples from South Africa (SA), 12 wood biomass from SA and 3 refusederived fuels from SA) used for this study were collected using a grab sampling method. Since there are no specific sampling protocols identified for biomass materials, the samples were collected with due care to obtain the most representative samples. For the coal samples, each sample was kept in a plastic bag (made from aluminium-coated polyester) and marked/labelled with a chosen number. The sample lumps were reduced to appropriate dimensions (10 mm) using a crusher (Rocklabs MK III). The samples were milled to a fraction of $250 \mu \mathrm{m}$ for proximate and ultimate analyses. The proximate analyses for these samples were carried out according to the ASTM D5142, with approximately $1 \mathrm{~g}$ used to estimate the $\mathrm{A}, \mathrm{VM}$ and $\mathrm{M}$ contents. The FC is expressed as the subtraction of the sum of moisture, volatile matter and ash contents from $100 \%$. The elemental analysis was conducted based on the ASTM 5373-14:2015for CHN with the use of a LECO CHN 628 with an add on $628 \mathrm{~S}$ module. Approximately $0.25 \mathrm{~g}$ of the samples were used for the temperature analyses of up to 
Table 1 Proximate and elemental analysis (wt\%) data obtained from the experimental tests

\begin{tabular}{|c|c|c|c|c|c|c|c|c|c|c|}
\hline Sample ID & Materials & $\mathrm{FC}$ & $\mathrm{VM}$ & $\mathrm{A}$ & M (Ar) & $\mathrm{C}$ & $\mathrm{H}$ & $\mathrm{N}$ & $\mathrm{O}$ & $\mathrm{S}$ \\
\hline DCFP & \multirow[t]{12}{*}{ Biomass } & 12.22 & 77.63 & 0.27 & 9.88 & 45.5 & 6.66 & $<0.0001$ & 37.57 & 0.12 \\
\hline DCGS & & 10.67 & 64.52 & 0.53 & 24.28 & 36.8 & 6.7 & 0.58 & 31.04 & 0.07 \\
\hline SPGB & & 15.14 & 73.89 & 0.81 & 10.16 & 44.5 & 6.57 & 0.57 & 37.27 & 0.12 \\
\hline PSP & & 15.2 & 57.05 & 1.05 & 26.69 & 41.1 & 6.35 & 0.8 & 29.19 & 0.07 \\
\hline DOCPGB & & 14.47 & 77.58 & 0.44 & 7.5 & 46.5 & 6.6 & 0.62 & 38.21 & 0.13 \\
\hline FWS & & 9.17 & 43.74 & 0.7 & 46.39 & 28.5 & 7.7 & 0.57 & 16.08 & 0.06 \\
\hline G(Fresh) & & 13.34 & 59.56 & 1.38 & 25.72 & 39 & 7.12 & 0.07 & 26.69 & 0.02 \\
\hline G(Dry) & & 15.92 & 75.94 & 1.74 & 6.4 & - & - & - & - & - \\
\hline G-2 years & & 12.02 & 53.02 & 1.77 & 33.19 & 32.61 & 7.65 & 0.11 & 24.65 & 0.02 \\
\hline G-2 years Dry & & 16.85 & 75.3 & 2.44 & 5.41 & - & - & - & - & - \\
\hline G-5-7 years & & 13.84 & 54.43 & 0.91 & 30.82 & 35.41 & 7.41 & 0.14 & 25.29 & 0.02 \\
\hline G5-7 years Dry & & 19.47 & 73.63 & 1.14 & 5.75 & - & - & - & - & - \\
\hline IW (RDF1) & \multirow[t]{3}{*}{ Refuse derived fuel } & 7.76 & 80.52 & 8.01 & 3.71 & 52.8 & 8 & 2.09 & 25.32 & 0.07 \\
\hline IW (RDF2) & & 8.07 & 85.16 & 3.61 & 3.16 & 56.4 & 9.11 & 2.05 & 25.51 & 0.16 \\
\hline IW (RDF3) & & 6.81 & 87.67 & 3.15 & 2.38 & 64.5 & 11.17 & 3.92 & 14.7 & 0.18 \\
\hline $\mathrm{S} 1$ & \multirow[t]{8}{*}{ SA coal } & 41.83 & 21.48 & 32.28 & 4.41 & 55.5 & 3.08 & 1.32 & 3.41 & \\
\hline S2 & & 41.37 & 21.35 & 32.82 & 4.45 & 55 & 3.09 & 1.29 & 3.35 & \\
\hline S3 & & 40.97 & 21.17 & 33.48 & 4.37 & 54.2 & 3.01 & 1.3 & 3.64 & \\
\hline S4 & & 42.24 & 21.33 & 32.08 & 4.35 & 53.2 & 3 & 1.24 & 6.13 & \\
\hline S5 & & 41 & 20.12 & 32.39 & 6.48 & 53.3 & 3.53 & 1.23 & 2.9 & \\
\hline S6 & & 40.96 & 22.13 & 32.56 & 4.35 & 54.4 & 3.52 & 1.3 & 3.87 & \\
\hline S7 & & 41.79 & 21.66 & 32.5 & 4.05 & 54.7 & 3.39 & 1.34 & 4.02 & \\
\hline S8 & & 42.28 & 21.34 & 32.73 & 3.64 & 54 & 3.36 & 1.32 & 4.95 & \\
\hline NIG1 & \multirow[t]{8}{*}{ NIG coal } & 44.52 & 30.51 & 8.35 & 16.62 & 60.72 & - & - & - & 0.35 \\
\hline NIG2 & & 43.28 & 31.35 & 7.72 & 17.05 & 63.2 & - & - & - & 0.27 \\
\hline NIG3 & & 40.28 & 33.66 & 4.83 & 21.24 & 58.8 & - & - & - & 0.39 \\
\hline NIG4 & & 39.6 & 33.88 & 5.59 & 20.93 & 60.61 & - & - & - & 0.39 \\
\hline NIG5 & & 43.36 & 31.15 & 6.81 & 18.68 & 61.65 & - & - & - & 0.31 \\
\hline NIG6 & & 43.83 & 30.98 & 8.12 & 17.07 & 62.46 & - & - & - & 0.35 \\
\hline NIG7 & & 42.7 & 32.91 & 6.54 & 17.85 & 62.11 & - & - & - & 0.35 \\
\hline NIG8 & & 42.79 & 31.61 & 8.54 & 17.06 & 62.54 & - & - & - & 0.36 \\
\hline
\end{tabular}

‘' Not determined

$1450{ }^{\circ} \mathrm{C}$ with an analyzing time of between 60 and $300 \mathrm{~s}$. A database of proximate and elemental analyses obtained from the experimental tests for the samples are presented in Table 1. To enable the general application of the proposed models, the data set was trained and validated using ANFIS, ANN, and MLR and compared with one another.

\section{Models development}

\subsection{Artificial neural network}

The ANN is a soft computing method that imitates the human brain in the processing of information, like reasoning, studying, memorizing and inducing a complex network. This is made possible through the interconnected structures comprising several simple processing neurons having the ability to perform large parallel computations for data processing and information representation (Dehghani and Ataee-pour 2011). To create an ANN model, there are various ways in which the neurons can be connected. The feed-forward (FF) ANN was suggested by Shahin et al. (2002) to solve extremely non-linear and complex problems such that time-dependent parameters are not involved in the input parameters. The multi-layer perceptron (MLP) neural network is a well-recognized FFANNs (Simpson 1990; Haykin 1999; Monjezi et al. 2013). MLP has several nodes/neurons in 3 layers i.e. input, 
hidden and an output connected together by weights. Du et al. (2002) and Kalinli et al. (2011) have successfully established the efficiency of MLP ANNs in high-dimensional functional approximation.

However, ANN requires the training of the network before the results can be interpreted. Various learning algorithms are used for training MLP-FF but the backpropagation (BP) algorithm is commonly applied (Rumelhart et al. 1986; Fausett 1994; Dreyfus 2005).

The mode of implementation of the BP-ANN is that the input data is imported into the input layer which initiates the propagation into the hidden neurons via the weights of connection. The input from each neuron in the input layer, $I_{i}$, is multiplied by the weight, $w_{i k}$. At each neuron, the summation of the input signals multiplied with their respective weights is determined and added to a threshold value referred to as the bias value, $b_{n k}$. To obtain the output of the node, the combined input, $J_{i}$, is subjected to a nonlinear transfer function (tan sigmoid or log sigmoid). The targeted output of the entire network can then be calculated by applying the same principle as in the case of the input node but in this case the transfer function, could be nonlinear such as a sigmoidal function or linear (Eq. (1)). In $\mathrm{BP}$, the signals are propagated from the input layer through the hidden layer to the output layer, known as forwardpass, then the system obtained values are compared to the targeted actual value and system error can be computed between the two values. The resulting errors are then returned to the system to update the weights known as backward-pass. In this process, the errors of both training and testing datasets are reduced. This procedure is repeated in the feed-forward-backpropagation ANN until the resulting errors have converged to the threshold level specified by the system's error function, such as the rootmean-squared error (RMSE). To build the ANN network, sufficient datasets are required though there is no extant rule to determine the number of datasets sufficient for the building of a suitable ANN model. Equation (1) shows the general form of the principle of operation of the ANN model.

$\Delta=f_{\text {sig/purlin }}\left\{b_{0}+\sum_{k=1}^{n}\left[f_{\text {sig }}\left(b_{h k}+\sum_{i=1}^{m} w_{i k} \Gamma_{i}\right)\right]\right\}$

where, $b_{0}$ is the bias in the output layer; $w_{k}$ is the weight of connection between the $k$ th of the hidden layer and the single output neuron; $b_{h k}$ is the bias in the $k$ th neuron of the hidden layer; $n$ is the number of neurons in the hidden layer; $w_{i k}$ is the weight of connection between the $i$ th input parameter and the hidden layer; $\Gamma_{i}$ is the input variable $i ; \Delta$ is the output variable; $f_{\text {purlin }}$ and $f_{\text {sig }}$ are the linear and nonlinear transfer functions respectively.

\subsection{ANN models for the predictions of elemental compositions}

The ANN model proposed in this study was created using MLP-FF that is trained with the BP training algorithm. Three different ANN models were performed predicting each of the $\mathrm{H}, \mathrm{O}$, and $\mathrm{C}$. This is necessary because the size of the matrixes of the targeted outputs is not equal for the elemental compositions and also to enable fair comparison with the ANFIS and MLR models. Four inputs variables representing the $\mathrm{A}, \mathrm{VM}, \mathrm{FC}$, and $\mathrm{M}$ contents were used in each of the models. A total of 28 experimental datasets conducted in this study as shown in Table 1 was used for developing ANN model for $\mathrm{C}$, while 20 parameters each were used for the respective ANN predictions of $\mathrm{H}$ and $\mathrm{O}$. The ANN model was performed in MATLAB $\subset$ environment using its embedded neural network toolbox. The input and output variables have been scaled between -1 and 1 using Eq. (2) to achieve the dimensional consistency of the parameters and also to eliminate the over-fitting of the trained network.

$Y_{i}=\frac{2\left(X_{i}-X_{\min }\right)}{X_{\max }-X_{\min }}-1$

where $Y_{i}$ is the scaled parameters, $X_{i}$ is the actual data to be scaled, $X_{\max }$ and $X_{\min }$ are the maximum and minimum values of the actual data, respectively.

The network architecture with one hidden layer was adopted in this study and the trial and error approach was used to arrive at the optimal network architecture. A three layers (one input, one hidden and one output layers) network with four neurons in the input layer, three neurons in the hidden layer, and one neuron in the output layer was chosen for the building of the proposed ANN models. A non-linear (TANSIG) transfer function was used for both the input layer and the output layer. The obtained optimal ANN architecture for the three proposed models is shown in Fig. 1.

The respective performances of the obtained models for each of the elemental compositions are shown in Fig. 2. The figures show that in each of the cases, the mean squared error decreases up to the points where the best performances were obtained and their values tend to reach asymptotic values after the best performance. The pattern of the curves for the training, validations, and testing are similar, indicating that the models are successful.

The regression plots of the proposed ANN models are also illustrated in Fig. 3. The figure shows that the $R$ values used to train, validate, and test the three models are above 


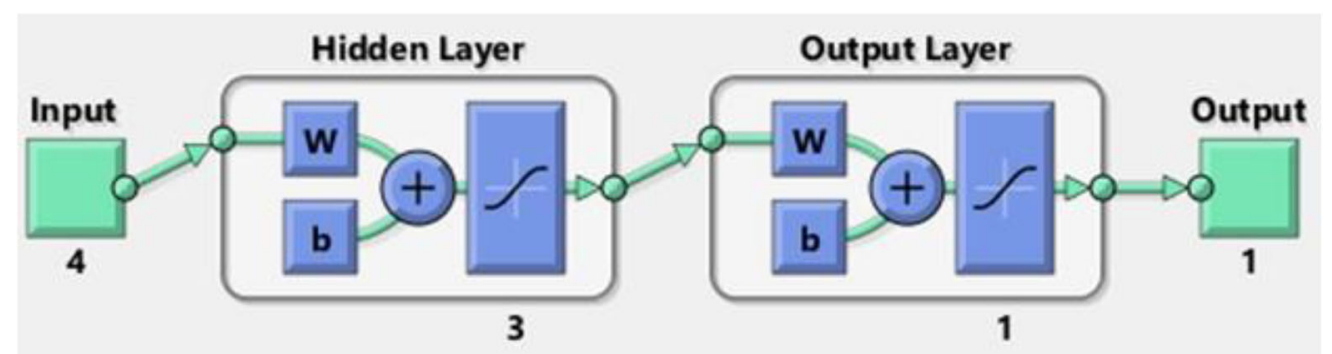

Fig. 1 Adopted ANN architecture for predicting the elemental composition
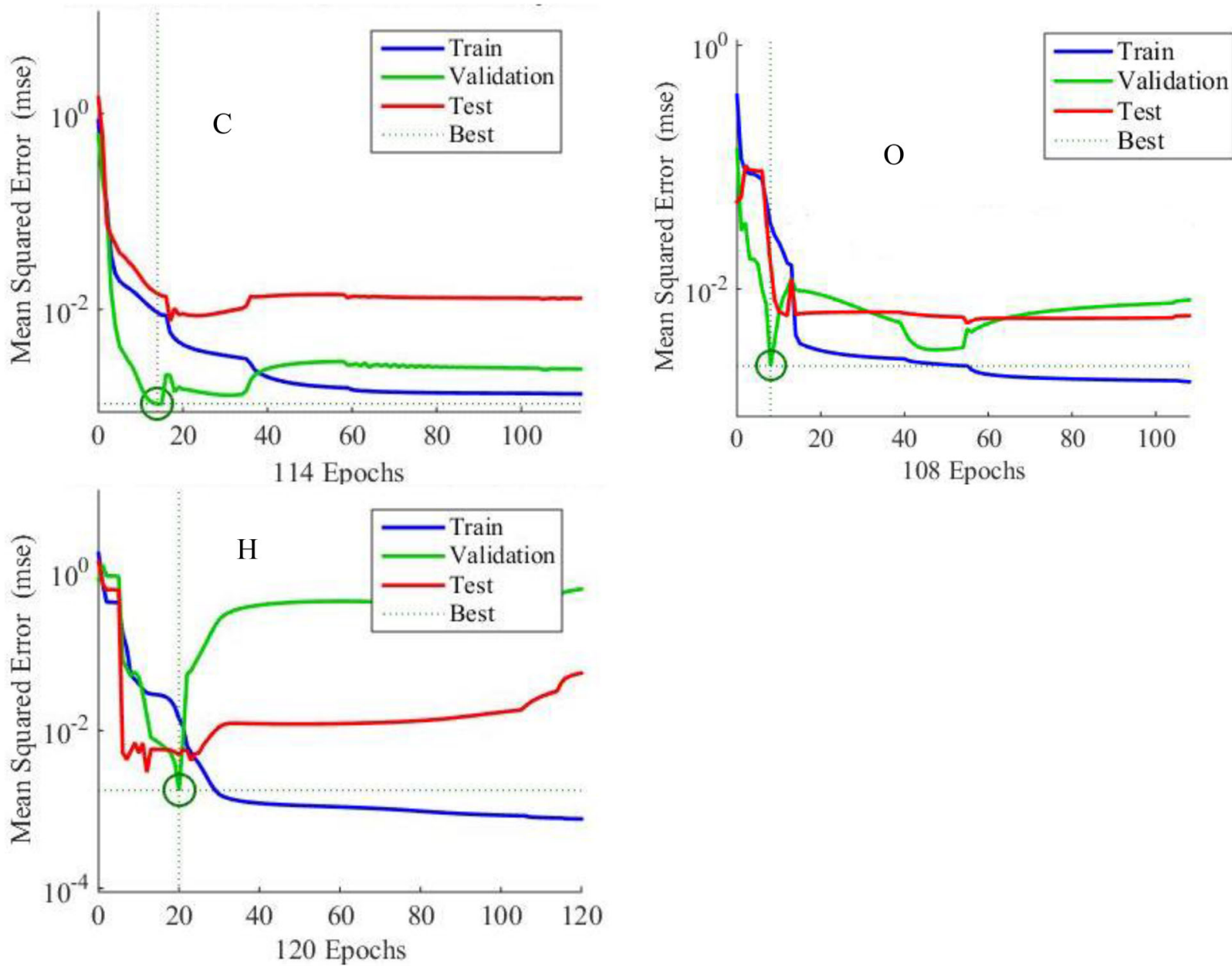

Fig. 2 Performances of the proposed ANN models for $\mathrm{C}, \mathrm{H}$, and $\mathrm{O}$ predictions

97\%. Hence, the proposed ANNs can successfully predict the elemental compositions of solid fuels.

To enable the easy application of the proposed ANN models for the predictions of elemental compositions of the solid fuels (i.e. coal and biomass), the proposed ANN models were transformed into the mathematical models through the weights and biases based on the ANN general equations presented in Eq. (1). The mathematical formulas obtained for $\mathrm{C}, \mathrm{H}$, and $\mathrm{O}$ are as presented in Eqs. (3) to (5). The predictions directly output from the ANN models and those of Eqs. (3), (4) and (5) were compared to validate the mathematically transformed ANN as illustrated in Fig. 4. It is found that the coefficient of determinants for the three models is $100 \%$ indicating that the proposed equations are replicates of their respective ANN models.

$$
\begin{aligned}
C= & 18 \tanh \left(-0.90519 x_{1}-1.7974 x_{2}+\cdots 1.6654 x_{3}\right. \\
& +0.59725)+46.5
\end{aligned}
$$

where 


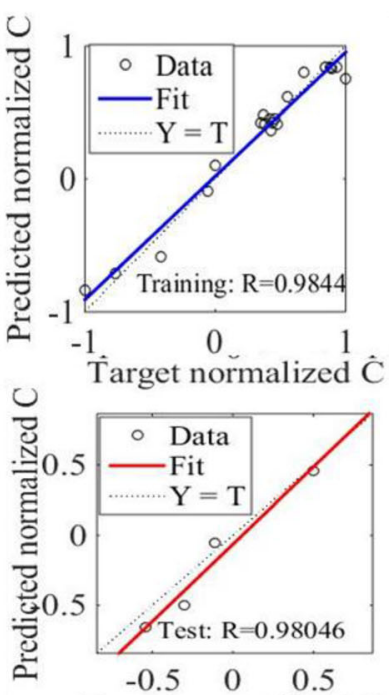

Target normalized C

(a)
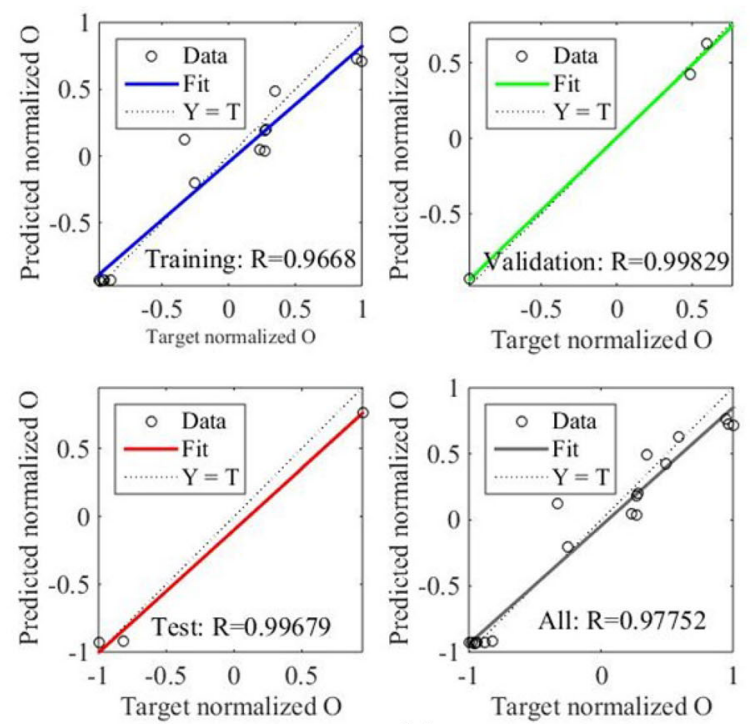

(c)
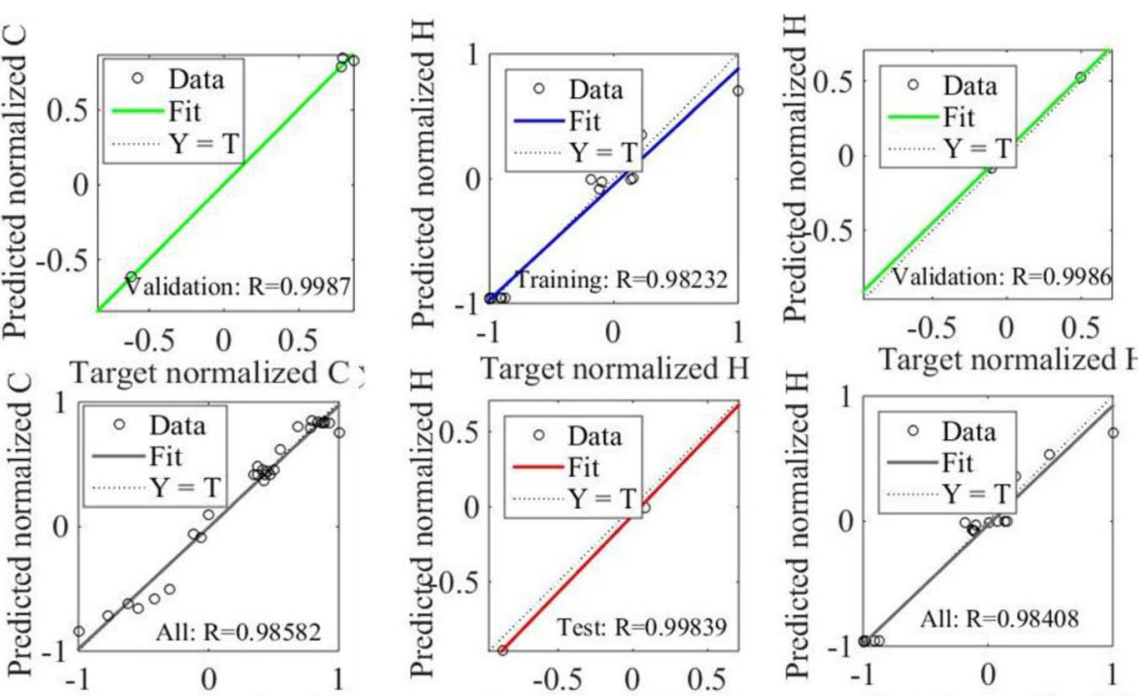

Target normalized $\mathrm{C}$

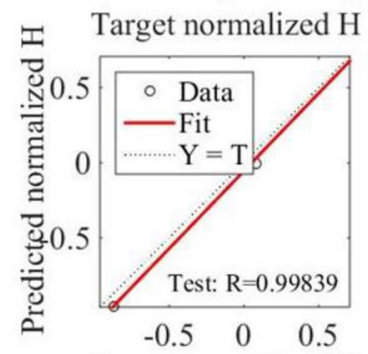

Target normalized $\mathrm{H}$

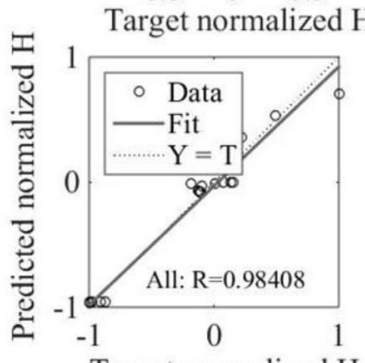

(b)
Target normalized $\mathrm{H}$

Fig. 3 a Regression graphs for the ANN models for C, b Regression graphs for the ANN models for H, $\mathbf{c}$ Regression graphs for the ANN models for $\mathrm{O}$

(a)

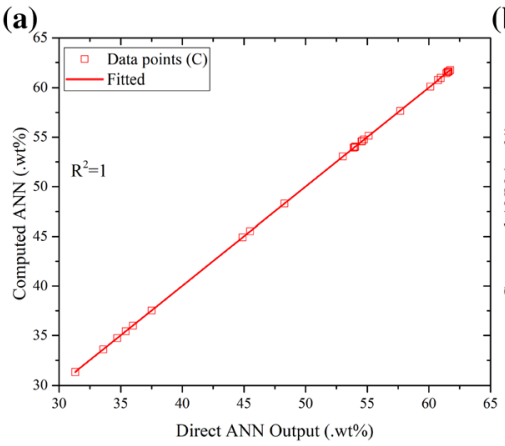

(b)

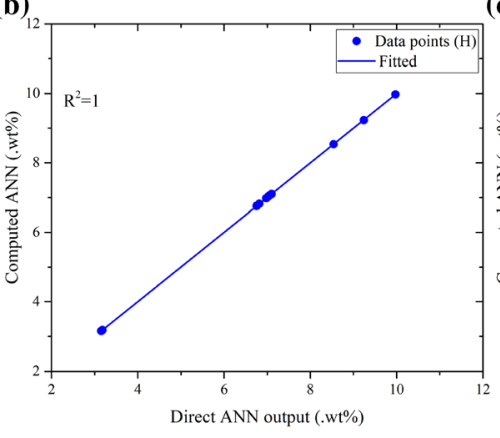

(c)

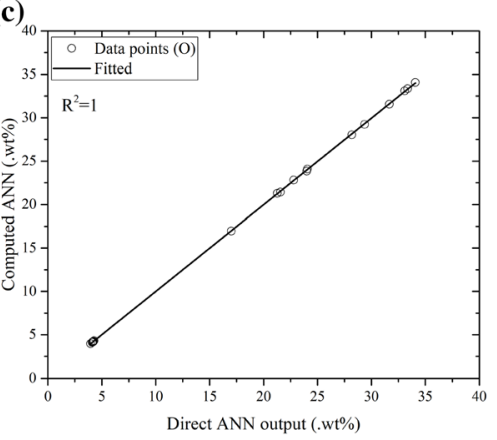

Fig. 4 Comparison of the ANN mathematical models with the direct ANN simulation outputs 


$$
\begin{aligned}
x_{1}= & \tanh (-3.9167+0.0232 F C-\cdots 0.00077 V M \\
& +0.0755 A-0.00296 M) \\
x_{2}= & \tanh (1.4133-0.0525 F C-\cdots 0.0079 V M \\
& +0.00669 A+0.00202 M) \\
x_{3}= & \tanh (-2.9884-0.06 F C+\cdots 0.0401 V M \\
& +0.022 A-0.0404 M) \\
H= & 4.085 \tanh \left(0.85756 y_{1}+1.078 y_{2}+\cdots 1.1217 y_{3}\right. \\
& -0.89233)+7.085
\end{aligned}
$$

where

$$
\begin{aligned}
y_{1}= & \tanh (8.0533-0.1429 F C+\cdots 0.0577 V M \\
& -0.2424 A-0.0986 M) \\
y_{2}= & \tanh (-8.0885-0.1288 F C+0.1052 V M \\
& +\cdots 0.1327 A-0.0631 M) \\
y_{3}= & \tanh (2.9588+0.05 F C-0.03036 V M \\
& -\cdots 0.1035 A+0.024 M) \\
O= & 17.655 \tanh \left(-0.55398 z_{1}-0.99659 z_{2}\right. \\
& \left.+\cdots 1.1272 z_{3}-0.9136\right)+20.555
\end{aligned}
$$

where

$$
\begin{aligned}
z_{1}= & \tanh (-1.4642+0.0683 F C-0.041 V M \\
& +\cdots 0.0149 A-0.0035 M) \\
z_{2}= & \tanh (-0.1809+0.0008 F C-0.02593 V M \\
& +\cdots 0.024 A+0.068 M) \\
z_{3}= & \tanh (-2.1145+0.057 F C+0.01333 V M \\
& -\cdots 0.0256 A+0.0745 M)
\end{aligned}
$$

\subsection{Adaptive Neuro-Fuzzy Inference System (ANFIS)}

ANFIS is a soft computing method that incorporates the concept of fuzzy logic into neural networks (Jang 1993). It is generally used in various aspects of engineering science and the earth sciences (Habibagahi 2002; Iphar 2012; Sahu et al. 2011; Sahu and Mahapatra 2013; Onifade et al. 2019). ANFIS has the ability to approximate any real continuous function on a compact set to any degree of accuracy (Jang et al. 1997). It uses linguistic information based on fuzzy logic and the learning capability of the ANN. ANFIS is a fuzzy mapping algorithm that replicates and evaluates the input and output data via a hybrid learning to estimate the optimal distribution of membership function on the basis of Tagaki-Sugeno-Kang (TSK) fuzzy inference system (Jang and Gulley 1995; Loukas 2001). ANFIS is essentially based on the fuzzy "If-Then" rules from the Takagi and Sugeno fuzzy model (Jang et al. 1997) as shown in Fig. 5. A typical Sugeno fuzzy system that has two input parameters, one output parameter as the result, and two rules are typically displayed in Fig. 5. The corresponding ANFIS structure of this system is also shown in
Fig. 5 (Rafiei-Sardooi et al. 2018; Seifi and Riahi 2018). Its rules are:

Rule 1: If $x$ is $A_{1}$ and $y$ is $B_{1}$ Then $f=p_{1} x+q_{1} y+r_{1}$

Rule 2: If $x$ is $A_{2}$ and $y$ is $B_{2}$ Then $f=p_{2} x+q_{2} y+r_{2}$

\subsection{Descriptions of node functions}

The ANFIS architecture has two node types which are square and circle nodes. In the square node, there is an unknown parameter while in circle node, there is no unknown parameter (i.e. only the multiplication of fuzzy membership functions and the normalization of the firing strengths take place in the two respective circle nodes). The node functions in the same layer have the same function family as explained below:

Layer 1: In this layer, every node output is fuzzified by membership grades of a fuzzy set equivalent to each input (Eq. (6)). The membership function of this fuzzy set may be triangular, trapezoidal, generalized bell and Gaussian membership functions.

$O_{1 i}=\mu_{A i}(x)$

where $x$ is input to node $i, \mathrm{O}_{1 i}$ is the membership grade of a fuzzy set $A_{i}$ and identifies the degree to which a certain input $x$ satisfies the quantifier $A_{i}$ and $\mu_{A i}$ is the membership function which could be any form of the afore-mentioned membership functions. For instance, the $\mu_{A i}$ for a typical bell-shaped function is given in Eq. (7).

$\mu_{A i}(x)=\frac{1}{1+\left[\left(\frac{x-c_{i}}{a_{i}}\right)^{2}\right]^{b_{i}}}$

where $a_{i}, b_{i}$, and $c_{i}$ are known as premise parameters in this layer. The parameters control the shape of the function.

Layer 2: Each node in this layer is a circle node labelled $M$, the output of which is the product of all Layer 1 outputs (Eq. (8)):

$O_{2 i}=w_{i}=\mu_{A i}(x) \times \mu_{B i}(x), \quad i=1,2$.

The output of each node in this layer is the firing strength of a rule.

Layer 3: This is a normalized layer. Every node labelled as encircled $N$ (Fig. 5). Every node in this layer normalizes the weight function generated from the preceding layer of the product. The $i$ th node measures the ratio of the firing strength of the $i$ th rules to the sum of all rule's firing strengths as presented in Eq. (9):

$O_{3 i}=\bar{w}_{i}=\frac{w_{i}}{w_{1}+w_{2}}, \quad i=1,2$.

Layer 4: This layer is the defuzzification layer. Each node $i$ in this layer is an adaptive node with a node function as described in Eq. (10). 

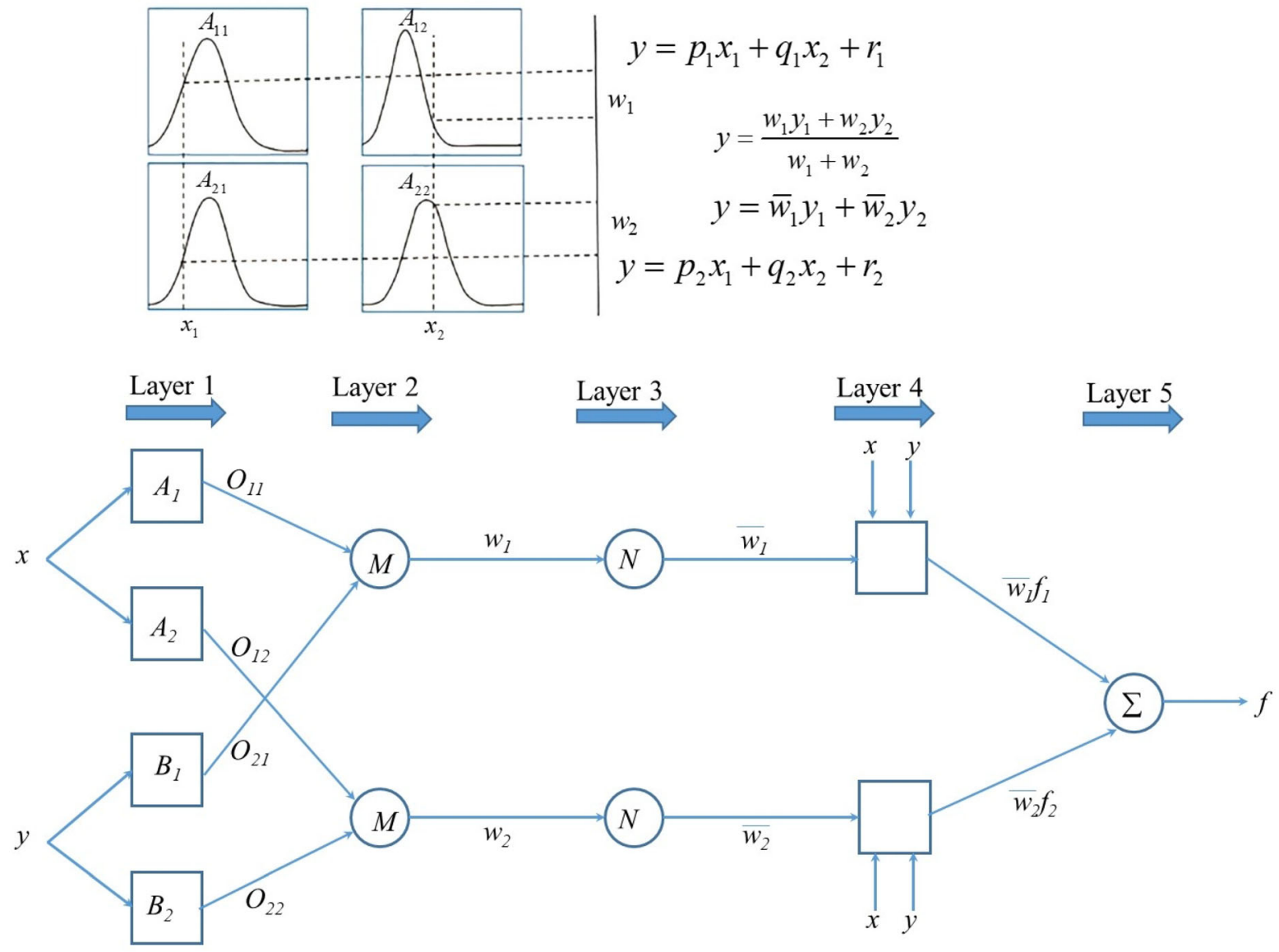

Fig. 5 A typical Sugeno fuzzy system with the corresponding ANFIS structure

$O_{4 i}=w_{i} f_{i}=\bar{w}_{i}\left(p_{i} x+q_{i} y+r_{i}\right), \quad i=1,2 .$,

where $w_{i}$ is the normalized firing strength from layer 3 . The parameter set of this node is $p_{i}, q_{i}$, and $r_{i}$. Parameters in this layer are termed the consequent parameters. For the input parameters with three (3) membership functions, for instance, the $f_{i}$ in Eq. (10) will be $\left(f_{i}=p_{i} x+q_{i} y+r_{i} z+s_{i}\right)$.

Layer 5: The single node in this layer is a fixed node characterised as $\Sigma$. It calculates the total output as the sum of all incoming signals as shown in Eq. (11).

$O_{5 i}=\sum \bar{w}_{i} f_{i}=\frac{\sum w_{i} f_{i}}{\sum w_{i}}, \quad i=1,2$.

\subsection{ANFIS model development for the prediction of elemental composition}

In this study, a five-layer ANFIS model was established to predict the elemental composition of coal and biomass. The Grid partitioning approach was used to create the FIS model and a hybrid technique was used to evaluate the premise and resulting parameters. A four inputs-one output model was employed to determine the $\mathrm{C}, \mathrm{H}$ and $\mathrm{O}$.
A Gaussian type membership function (guessmf) was selected for inputs and constant type membership function was used for output when obtaining the fuzzy inference system for the $\mathrm{C}$ and $\mathrm{H}$. The triangular membership function (trimf) was chosen for the input in the case of $\mathrm{O}$ and the constant type membership function was also used for the output in the case of O. Each of the input membership functions was categorised into three linguistics variables. The low (L); high (H) and very high (VH) linguistic variables were used for the FC and VM while very low (VL); low (L) and high (H) were used for the A and M, respectively. A typical membership function for input 2 (VM) and input 3 (A) with the respective Gaussian and triangular membership functions is shown in Fig. 6. The data set was selected randomly but included the highest and lowest values. The data set was normalized within the range of 0 and 1 . The ANFIS model was implemented in MATLAB environment.

Eighty-one rules in total were created in each of the models (Fig. 7). The predictive capability of the models was tested using eight additional data points having the same distribution as the training data set for the carbon while four additional data set each was used for both 

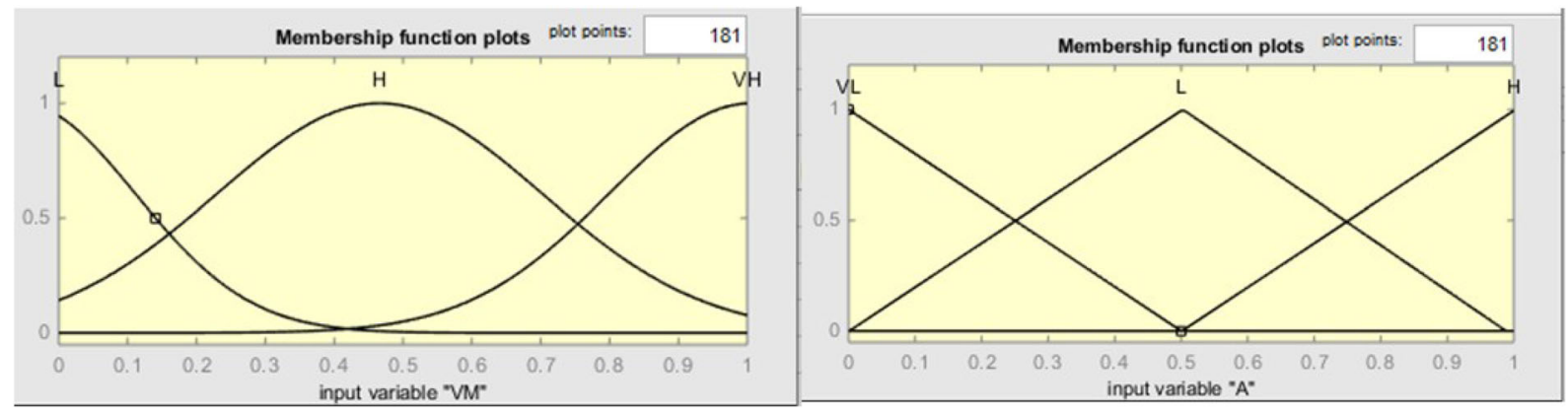

Fig. 6 Membership function plots for the input variables

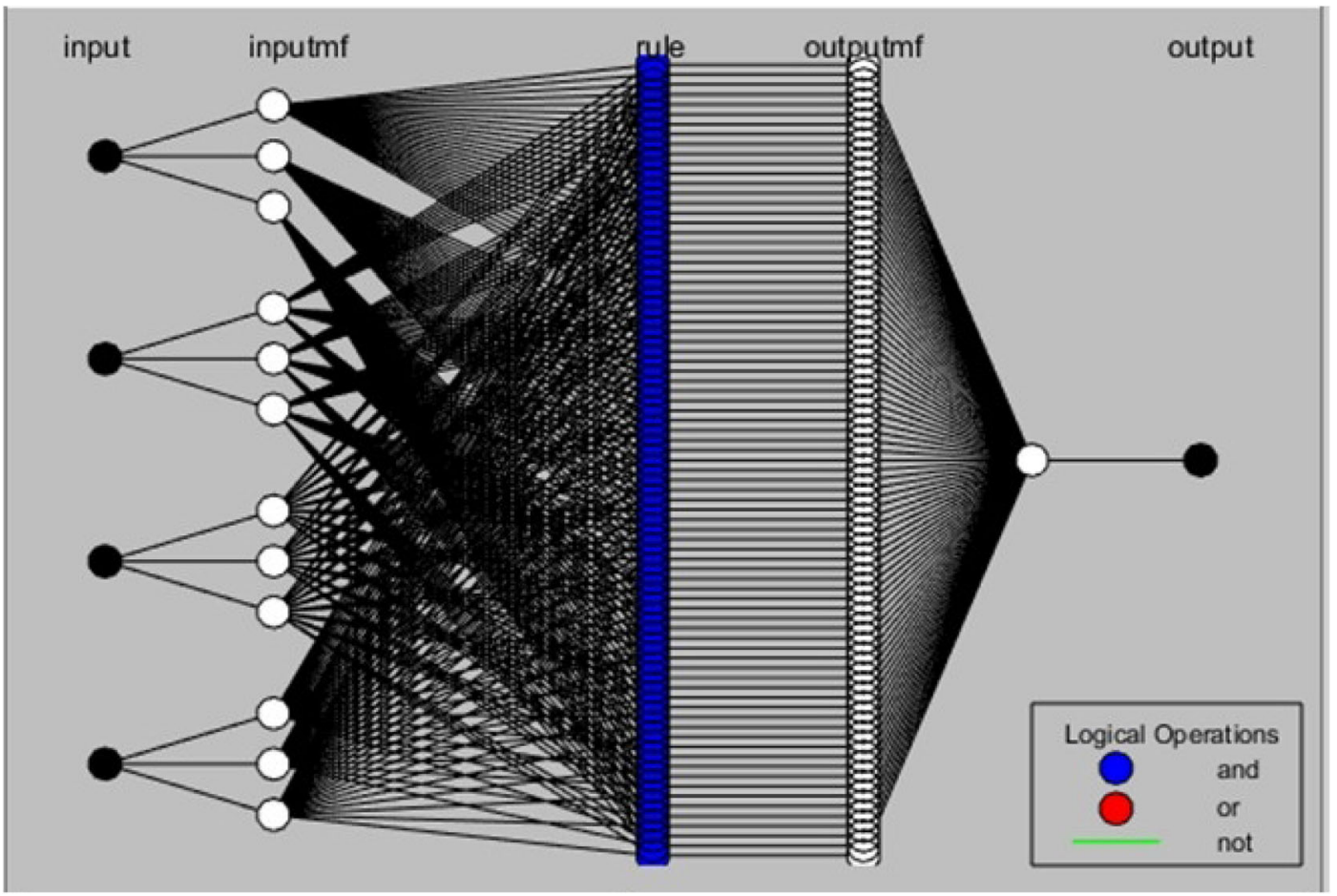

Fig. 7 ANFIS model structure

hydrogen $(\mathrm{H})$ and oxygen $(\mathrm{O})$ testing, respectively. The overall performance of the models was compared with predictions of the other model using the whole data sets used in developing the models. The premise and the consequence parameters are output as presented in Tables 2 and 3 , respectively.

\subsection{Multilinear regression (MLR)}

The multilinear regression technique is widely used in different engineering fields to solve a wide range of problems. For instance, the MLR was used by Shen et al. (2010) and Parikh et al. (2007) for predicting the elemental compositions of fuels. In the area of geotechnical engineering, MLR has been used to predict the strength of rock, rock fragmentation and shear strength parameters by
Gokceoglu and Zorlu (2004), Bahrami et al. (2011) and Jahed et al. (2014), respectively. MLR is normally utilized to establish a relationship between the dependent and independent variables (Onifade 2018; Onifade and Genc 2018). Hence, MLR measures the influence of the dependent variable on the independent variable. For the regression involving one dependent and one independent variable, the general regression equation is shown in Eq. (12).

$D=\beta_{0}+\beta_{1} E$

where $\beta$ is constant, $D$ and $E$ are dependent and independent variables, respectively. The equation can be extended to accommodate more than one independent variables as presented in Eq. (13). 
Table 2 Premise parameters

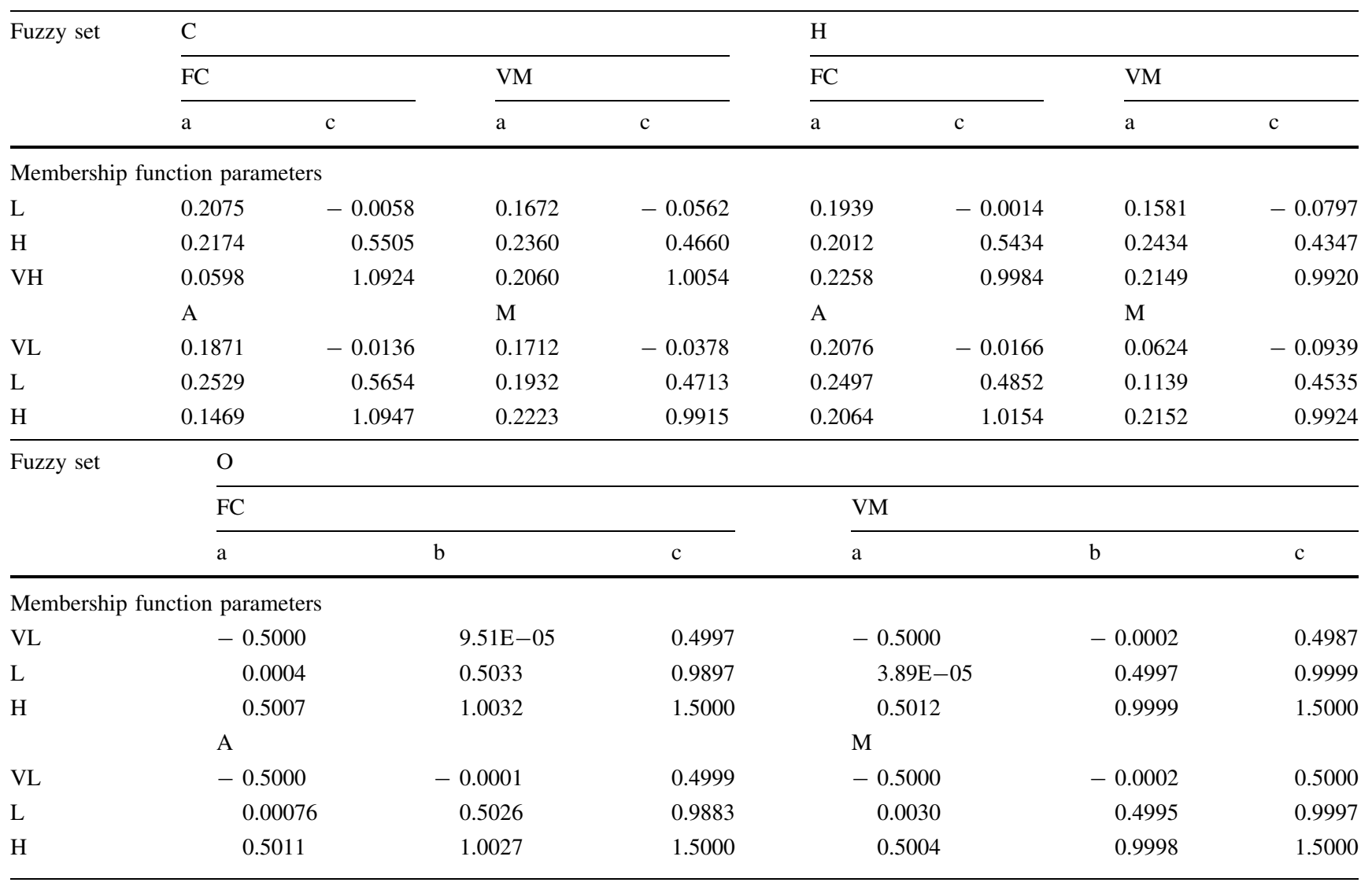

$D=\beta_{0}+\beta_{1} E_{1}+\beta_{2} E_{2}+\beta_{3} E_{3}+\cdots \beta_{n} E_{n}$

where $E_{1}, E_{2}, E_{3}, \ldots E_{n}$ is different independent variables to predict $D$.

The MLR was used in this study for the prediction of the elemental composition of fuels (coal and biomass). The dependent variables are $\mathrm{C}, \mathrm{H}$, and $\mathrm{O}$ whereas the independent variables are FC, VM, A, and M. The MLR was implemented with the OriginPro ${ }^{\odot}$ software. To do this, the dependent and independent variables were imported into the OriginPro ${ }^{(}$software and under the analysis drawdown menu, the multilinear regression was selected to perform the required MLR analysis. The obtained MLR equations for the three dependent variables are as presented in Eqs. (14) to (16).

$$
\begin{aligned}
C= & 348.4658-2.36909 F C-\cdots 2.97122 V M-3.5354 A \\
& -3.67567 M
\end{aligned}
$$$$
\begin{aligned}
H= & -6156.21+61.44349 F C+\cdots 61.66506 V M \\
& +61.74224 A+61.65248 M
\end{aligned}
$$

$$
\begin{aligned}
O= & 31071.46-309.621 F C-\cdots 310.437 V M \\
& -312.201 A-310.789 M
\end{aligned}
$$

\section{Results and discussion}

\subsection{Model comparison}

The models developed in the proposed study (Figs. 8, 9, 10) for the prediction of the most important elemental compositions using the MLR, ANN and ANFIS were compared with the models suggested in the literature (Shen et al. 2010, Parikh et al. 2007, Nhuchhen, 2016). Shen et al. (2010) proposed prediction equations shown in Eqs. (17) to (19) to predict the elemental composition of biomass from the proximate analysis. Parikh et al. (2007) also derived expressions for the calculation of the elemental composition of biomass materials from their proximate analysis as shown in Eqs. (20) to (22) (Table 4). Similarly, Nhuchhen (2016) proposed models for the predictions of $\mathrm{C}, \mathrm{H}$, and $\mathrm{O}$ compositions of raw and torrefied biomass using proximate analysis as shown in Eqs. (23) to (25) in Table 4. The models proposed by Shen et al. (2010), Parikh et al. (2007) and Nhuchhen (2016) are based on regression analysis. The 
Table 3 Consequence parameters

\begin{tabular}{|c|c|c|c|c|c|c|c|}
\hline Rule No. & $\mathrm{C}$ & $\mathrm{H}$ & $\mathrm{O}$ & Rule No. & $\mathrm{C}$ & $\mathrm{H}$ & $\mathrm{O}$ \\
\hline 1 & 0.000269 & $-5.55 \mathrm{E}-08$ & 0 & 21 & -0.13223 & -0.97493 & -0.70124 \\
\hline 2 & -0.03584 & 0.007475 & 1.263766 & 22 & 0.660464 & 0.617999 & 0.15049 \\
\hline 3 & 0.367674 & 0.068776 & -2.29527 & 23 & 0.043413 & 0.783686 & -0.7739 \\
\hline 4 & -0.01069 & $-1.78 \mathrm{E}-05$ & 0 & 24 & -0.0132 & -0.08864 & -0.05804 \\
\hline 5 & -0.00458 & 0.001518 & 0.122963 & 25 & $-8.57 \mathrm{E}-07$ & 0.00011 & 0 \\
\hline 6 & 0.034003 & 0.009663 & 0.003793 & 26 & $-9.07 \mathrm{E}-08$ & 0.00013 & 0 \\
\hline 7 & -0.04246 & -0.0002 & 0 & 27 & $-1.22 \mathrm{E}-10$ & $2.49 \mathrm{E}-06$ & 0 \\
\hline 8 & -0.00467 & $9.58 \mathrm{E}-06$ & 0 & 28 & 2.052888 & $-6.12 \mathrm{E}-05$ & 0 \\
\hline 9 & $-6.19 \mathrm{E}-06$ & $2.80 \mathrm{E}-07$ & 0 & 29 & 0.5354 & -0.00594 & 0.521294 \\
\hline 10 & -0.54567 & -0.21429 & 0.374382 & 30 & -0.24181 & 0.00431 & -0.12822 \\
\hline 11 & 0.330534 & -0.25255 & -0.15629 & 31 & 3.19066 & -0.3794 & -0.16027 \\
\hline 12 & 0.128339 & 0.725566 & 1.687672 & 32 & 0.982163 & 0.033292 & 0.046702 \\
\hline 13 & 0.002659 & -0.00618 & 0.03973 & 33 & -0.13389 & 0.000602 & 0.021977 \\
\hline 14 & 0.084231 & 5.416158 & -0.1133 & 34 & 1.815552 & -2.79185 & 1.111512 \\
\hline 15 & -0.01717 & -0.39114 & 2.124643 & 35 & -4.35343 & 0.179801 & 0.292338 \\
\hline 16 & -0.00989 & $-3.15 \mathrm{E}-05$ & 0 & 36 & -0.00721 & 0.000213 & 0 \\
\hline 17 & -0.00107 & 0.000835 & 0 & 37 & 2.200396 & -0.2023 & 1.077944 \\
\hline 18 & $-1.43 \mathrm{E}-06$ & $-9.90 \mathrm{E}-05$ & 0 & 38 & 0.798268 & -0.31535 & 1.803183 \\
\hline 19 & 1.333115 & 1.280082 & 0.372259 & 39 & -1.80916 & 1.439211 & -0.83538 \\
\hline 20 & -0.18176 & 0.408581 & 2.567847 & 40 & -0.16221 & -0.0668 & 0.022381 \\
\hline Rule No. & $\mathrm{C}$ & $\mathrm{H}$ & $\mathrm{O}$ & Rule No. & $\mathrm{C}$ & $\mathrm{H}$ & $\mathrm{O}$ \\
\hline 41 & 1.768118 & 1.159794 & -0.02077 & 61 & 2.831948 & -0.52799 & 0.189404 \\
\hline 42 & -0.32267 & 0.174066 & 0.80123 & 62 & -1.14449 & 0.705989 & -1.65825 \\
\hline 43 & -6.08074 & -0.27758 & -0.09156 & 63 & -0.00229 & -0.02651 & 0 \\
\hline 44 & -1.44597 & 0.033948 & -0.01137 & 64 & 1.83319 & -0.00215 & 0 \\
\hline 45 & -0.00221 & -0.00019 & 0 & 65 & -0.36877 & -0.14276 & 0 \\
\hline 46 & -0.28783 & -0.64251 & 1.968342 & 66 & -0.17109 & -0.00412 & 0 \\
\hline 47 & 0.424009 & 0.634454 & -0.02027 & 67 & 0.102522 & -0.10097 & 0.036951 \\
\hline 48 & -0.03492 & 0.220269 & -0.1278 & 68 & 1.019777 & -0.00878 & -0.00178 \\
\hline 49 & 0.005584 & -0.09124 & 0.057223 & 69 & -0.12641 & -0.00279 & 0 \\
\hline 50 & 0.054524 & 0.282094 & -0.3883 & 70 & 1.018698 & 4.273531 & -2.37353 \\
\hline 51 & -0.0031 & 0.058567 & -0.02009 & 71 & -0.1586 & 0.051936 & -0.45608 \\
\hline 52 & -0.00114 & $6.46 \mathrm{E}-05$ & 0 & 72 & -0.00035 & -0.00962 & 0 \\
\hline 53 & -0.00017 & $4.00 \mathrm{E}-05$ & 0 & 73 & 0.000821 & -0.00654 & 0 \\
\hline 54 & $-2.41 \mathrm{E}-07$ & $4.75 \mathrm{E}-06$ & 0 & 74 & -0.00099 & -0.0335 & 0 \\
\hline 55 & 2.119398 & -0.00091 & 0 & 75 & -0.0001 & -0.00046 & 0 \\
\hline 56 & 1.495309 & -0.00011 & 0 & 76 & 0.000731 & -0.0009 & 0 \\
\hline 57 & -0.14283 & $1.53 \mathrm{E}-05$ & 0 & 77 & -0.00048 & -0.00466 & 0 \\
\hline 58 & -9.09923 & -2.58485 & 2.352429 & 78 & $-8.10 \mathrm{E}-05$ & $4.03 \mathrm{E}-05$ & 0 \\
\hline 59 & 2.254854 & 0.122212 & 0.293957 & 79 & 0.000104 & 0.001589 & 0 \\
\hline \multirow[t]{2}{*}{60} & -0.0914 & -0.0041 & 0 & 80 & $-5.86 \mathrm{E}-06$ & $-1.06 \mathrm{E}-05$ & 0 \\
\hline & & & & 81 & $-1.66 \mathrm{E}-08$ & $-1.60 \mathrm{E}-06$ & 0 \\
\hline
\end{tabular}

predictions of their proposed models were compared with the predictions of the three models proposed in this study as presented in Figs. 8, 9, 10.
For the predicted C (Fig. 8), the $R^{2}$ values of the model suggested by Shen et al. (2010), Parikh et al. (2007) and Nhuchhen (2016) are $0.2513,0.4474$ and 0.8327 , respectively while the $R^{2}$ value of the predictions of the MLR, 


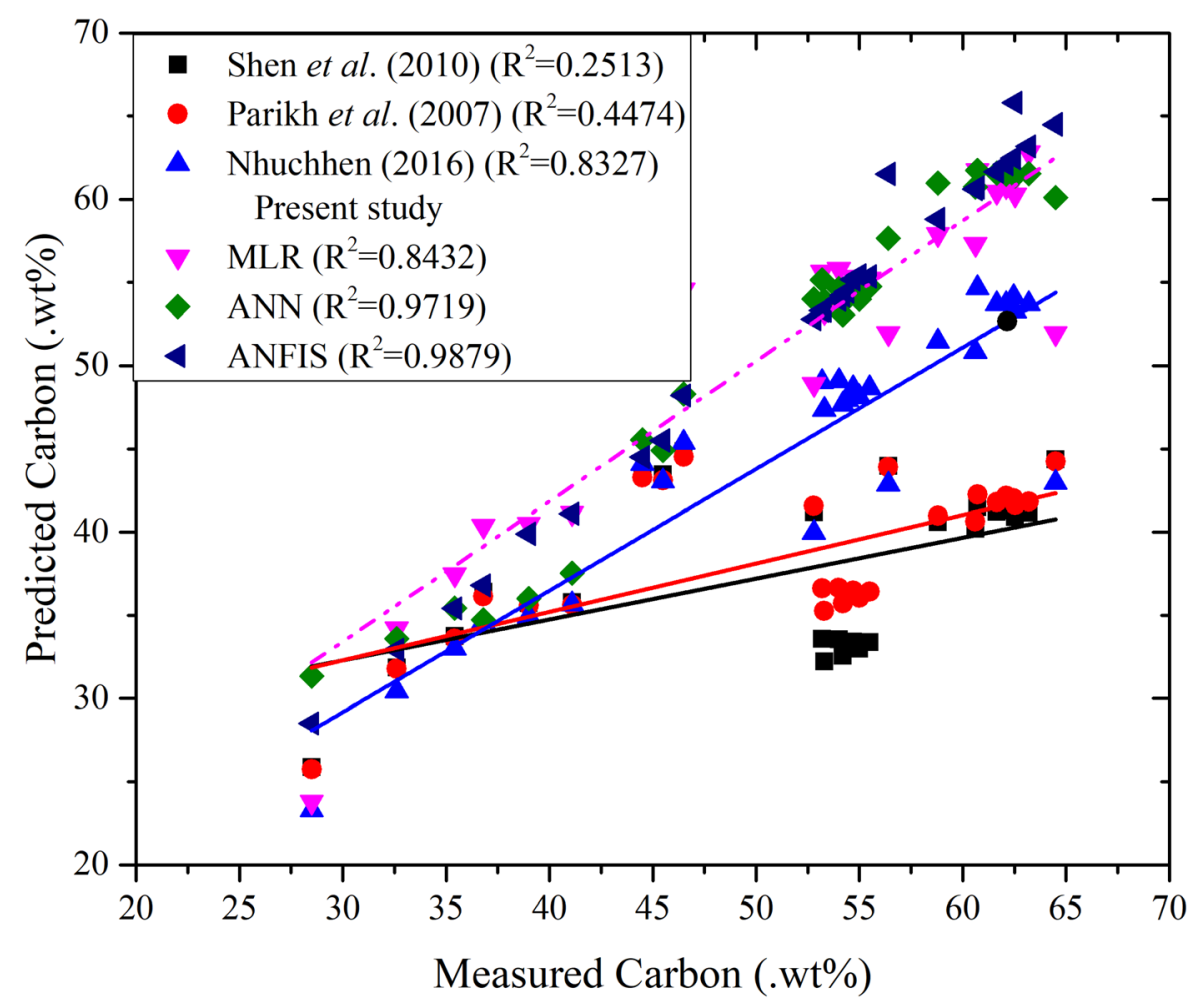

Fig. 8 Comparison of the predicted $\mathrm{C}$ with the measured carbon

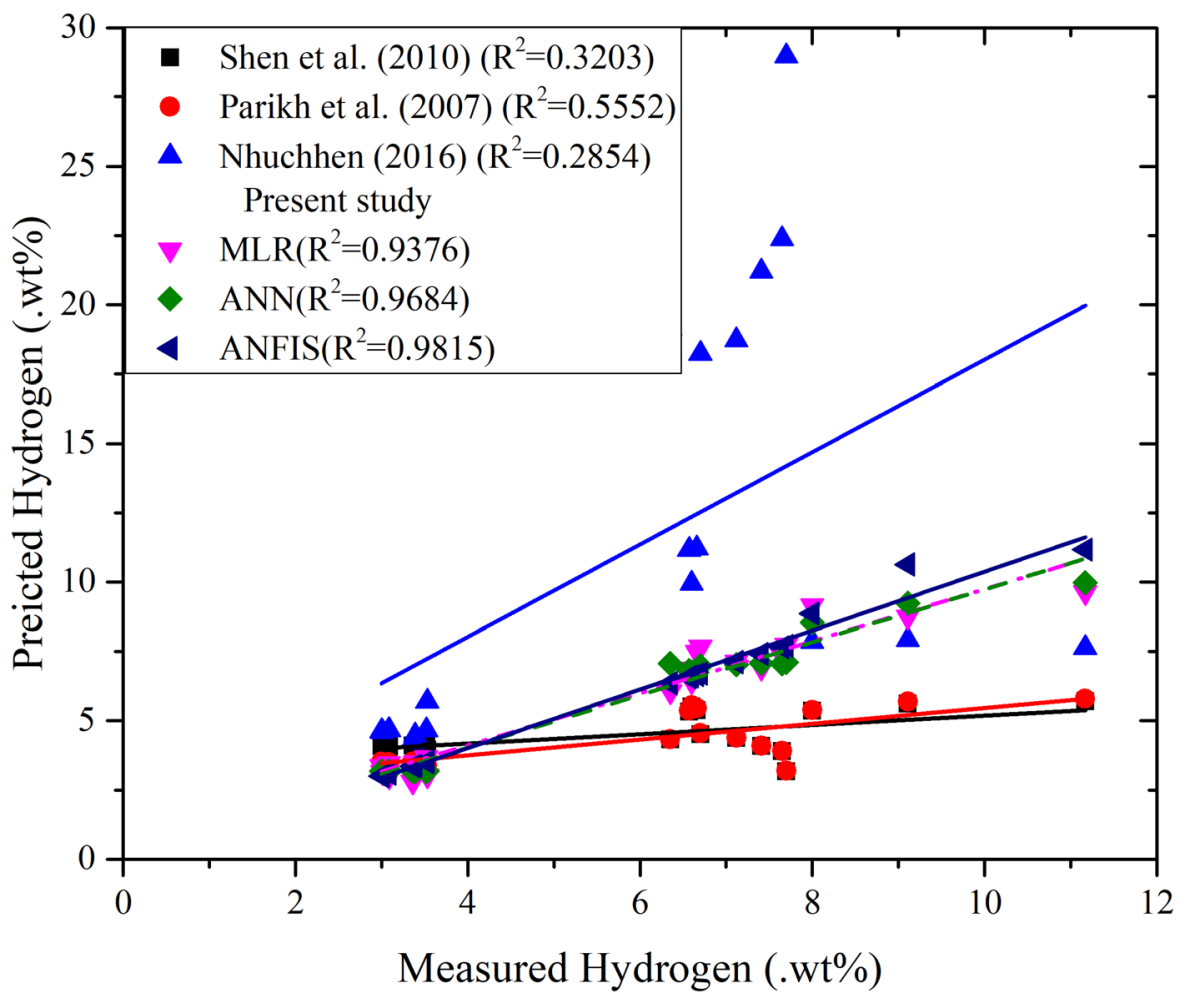

Fig. 9 Comparison of the predicted $\mathrm{H}$ with the measured hydrogen 


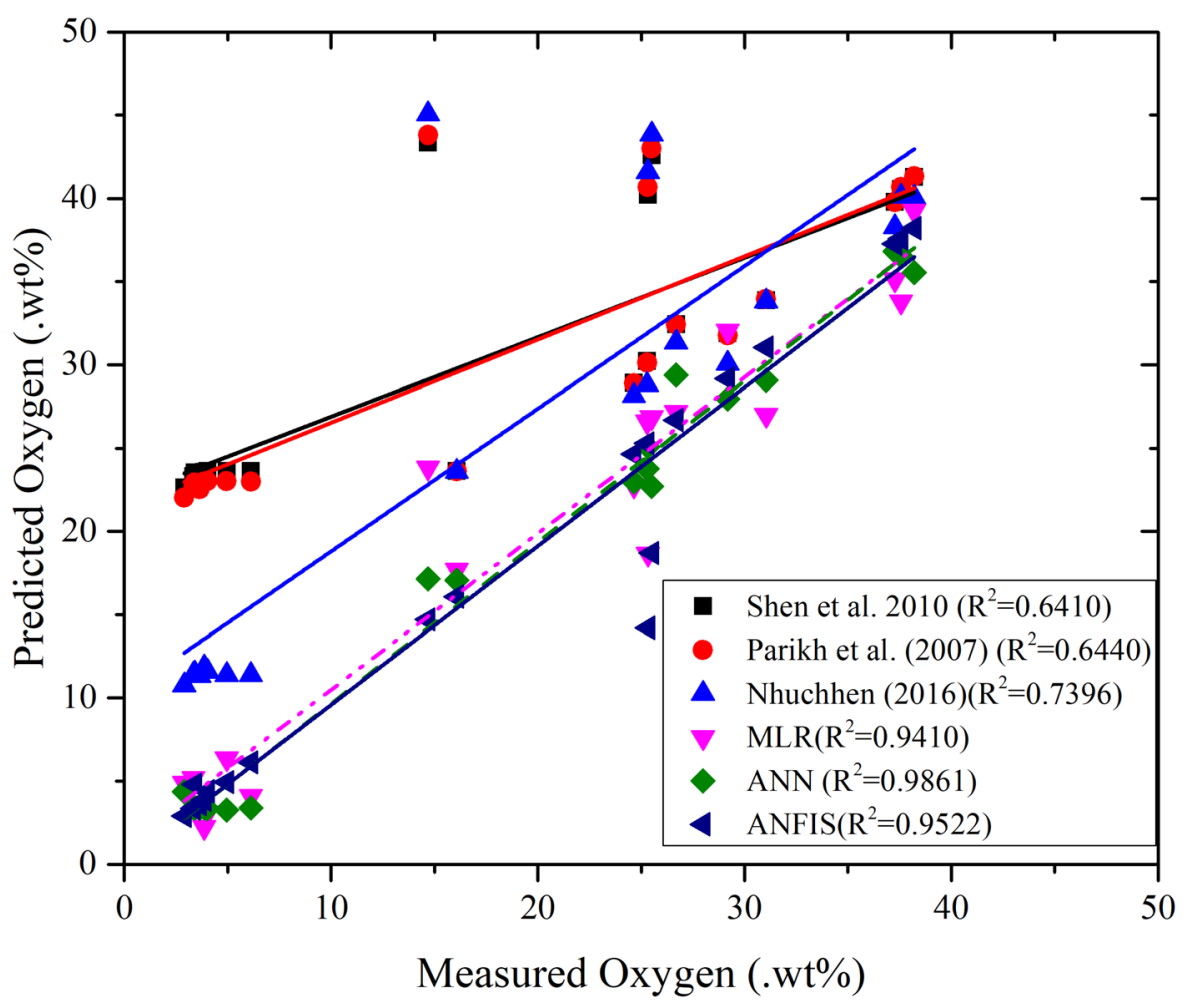

Fig. 10 Comparison of the predicted $\mathrm{O}$ with the measured oxygen

Table 4 Adopted models for the validations of the proposed models

\begin{tabular}{|c|c|c|c|}
\hline $\mathrm{S} / \mathrm{N}$ & Existing model & Reference & Eq. number \\
\hline 1 & $C=0.635 F C+0.46 V M-0.095 A$ & Shen et al. (2010) & $(17)$ \\
\hline 2 & $H=0.059 F C+0.06 V M+0.01 A$ & & $(18)$ \\
\hline 3 & $O=0.34 F C+0.469 V M-0.023 A$ & & (19) \\
\hline 4 & $C=0.637 F C+0.455 V M$ & Parikh et al. (2007) & $(20)$ \\
\hline 5 & $H=0.052 F C+0.062 V M$ & & $(21)$ \\
\hline 6 & $O=0.304 F C+0.476 V M$ & & $(22)$ \\
\hline 7 & $C=1.0396 F C+0.0757 V M^{1.3773}$ & Nhuchhen (2016) & $(23)$ \\
\hline 8 & $H=55.3678-0.483 F C-0.5319 V M-0.56 A$ & & $(24)$ \\
\hline 9 & $O=-0.0198 F C+0.7244 V M^{0.9239}$ & & $(25)$ \\
\hline
\end{tabular}

ANN, and ANFIS are 0.8432, 0.9719, 0.9879, respectively. Based on this comparison, the proposed models give better predictions of $\mathrm{C}$ than the three existing models compared in this study. On the other hand, the $R^{2}$ values of the predicted $\mathrm{H}$ using the Shen et al. (2010), Parikh et al. (2007) and Nhuchhen (2016) are $0.3203,0.5552$ and 0.2854 , respectively while those of the present study using MLR, ANN and ANFIS are 0.9376, 0.9684 and 0.9815 , respectively (Fig. 9). For the O, the $R^{2}$ values for the Shen et al. (2010), Parikh et al. (2007) and Nhuchhen (2016) are 0.641, 0.644, and 0.7396, respectively while those of MLR, ANN, and ANFIS are 0.941, 0.9861, and 0.9522, respectively
(Fig. 10). In all the compared cases, the proposed models have the highest coefficient of correlations than the existing models. Hence, they can give reasonable predictions of the $\mathrm{C}, \mathrm{H}$, and $\mathrm{O}$. To further showcase the performances of the proposed models, the error analysis was conducted as presented in the next subsection.

\subsection{Error analysis}

The performance of the proposed models and the models obtained in the literature was evaluated using three forms of estimation errors, which are the mean absolute error 
Table 5 Error analysis

\begin{tabular}{|c|c|c|c|c|c|c|c|c|c|}
\hline \multirow[t]{2}{*}{ Model } & \multicolumn{3}{|l|}{$\mathrm{C}$} & \multicolumn{3}{|l|}{$\mathrm{H}$} & \multicolumn{3}{|l|}{$\mathrm{O}$} \\
\hline & MAE & AAE & $\mathrm{ABE}$ & MAE & AAE & $\mathrm{ABE}$ & MAE & AAE & $\mathrm{ABE}$ \\
\hline Shen et al. (2010) & 14.141 & 0.25 & -0.25 & 2.011 & 0.317 & -0.113 & 12.6 & 2.263 & 2.263 \\
\hline Parikh et al. (2007) & 13.151 & 0.233 & -0.233 & 1.776 & 0.248 & -0.181 & 12.423 & 2.205 & 2.205 \\
\hline Nhuchhen (2016) & 6.698 & 0.124 & -0.124 & 5.739 & 0.894 & 0.848 & 7.615 & 1.017 & 1.017 \\
\hline MLR & 2.658 & 0.055 & 0.005 & 0.439 & 0.076 & 0.005 & 2.307 & 0.205 & 0.043 \\
\hline ANN & 1.317 & 0.027 & -0.002 & 0.328 & 0.055 & -0.355 & 1.353 & 0.123 & -0.038 \\
\hline ANFIS & 0.45 & 0.008 & 0.008 & 0.122 & 0.014 & 0.014 & 0.988 & 0.06 & -0.01 \\
\hline
\end{tabular}

(MAE) (Eq. (26)), average absolute error (AAE) (Eq. (27)), and average biased error (ABE) (Eq. (28)) as presented in Table 5.

$M A E=\frac{1}{n} \sum_{i=1}^{n}\left|E_{i}-P_{i}\right|$
$A A E=\frac{1}{n} \sum_{i=1}^{n}\left(\left|P_{i}-E_{i}\right| / E_{i}\right)$
$A B E=\frac{1}{n} \sum_{i=1}^{n}\left(P_{i}-E_{i}\right) / E_{i}$

where $E$ and $P$ represent the experimentally measured and predicted elemental compositions of the solid fuels, while $n$ is the number of sample data points used for the model developments. The AAE estimates the degree of closeness between the predicted and measured elemental compositions, the $\mathrm{ABE}$ computes the degree of the bias of the models' errors. The smaller the absolute value of the AAE
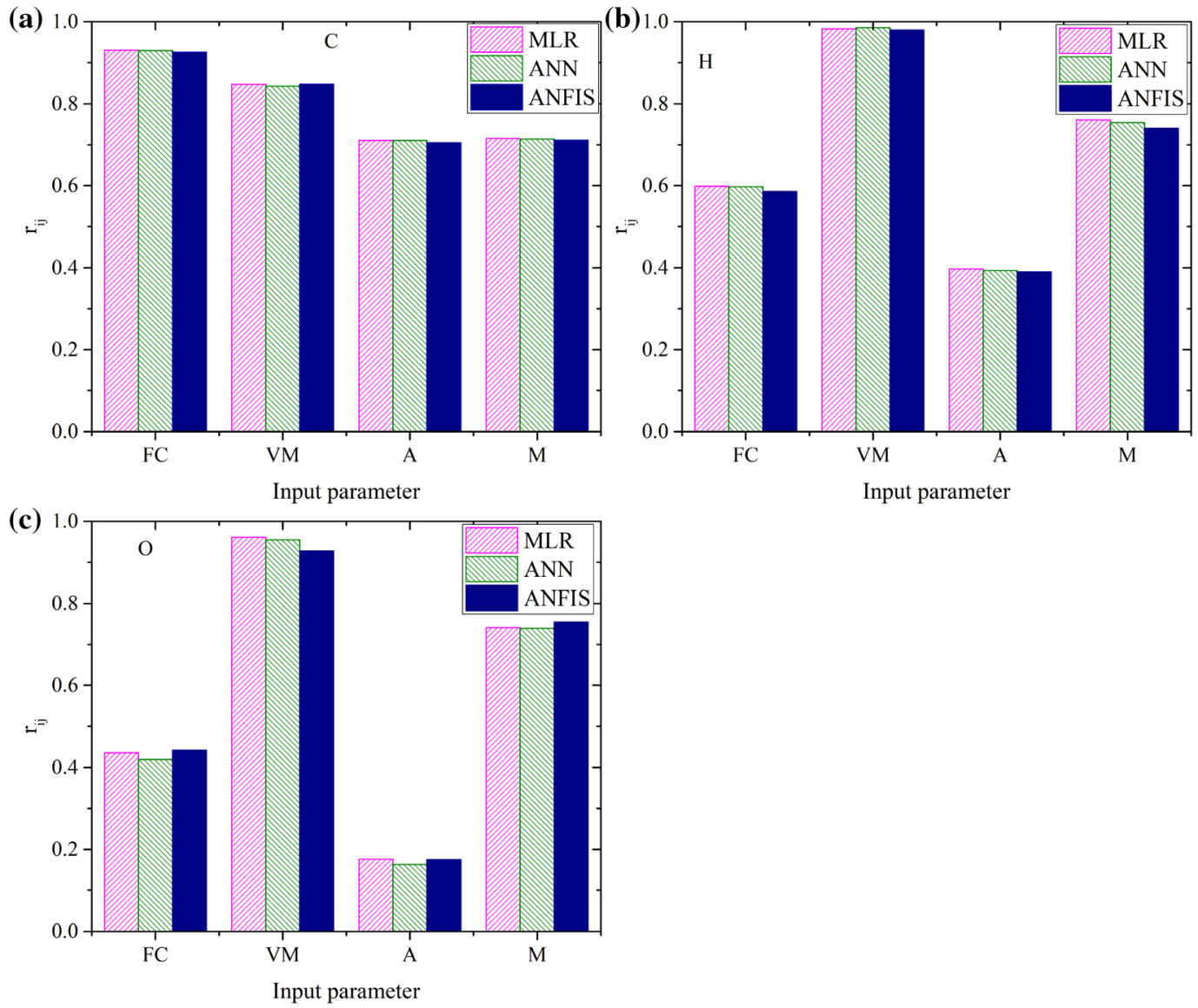

Fig. 11 Strength of the input paramet 
is, the smaller the bias of the correlation while a positive $\mathrm{ABE}$ value depicts that the average of the predicted value of the elemental composition is more than the experimentally measured one. Similarly, the MAE gives an apparent amount of error in the same unit that the physical quantity has. In addition, $R^{2}$ indicates the degree of goodness of the proposed correlations respectively (Shen et al. 2010; Nhuchhen 2016). The models having the least MAE and high $R^{2}$ values were selected as the best models for predicting the elemental compositions of solid fuels.

The error analysis performed in this study is as presented in Table 5. For the MAE error, the ANFIS model has the least value for the carbon, hydrogen, and oxygen while Shen et al. (2010) model has the highest. In the case of AAE, ANFIS model also has the smallest values for all the predicted elemental compositions which imply that ANFIS prediction is closer to the experimental predictions while Shen et al. (2010) model has the highest AAE in both $\mathrm{C}$ and $\mathrm{O}$ and AAE of Nhuchhen (2016) model is the highest in $\mathrm{H}$. The ABE for both the ANFIS and MLR in the case of $\mathrm{C}$ are positive while those of the remaining models are negative indicating that ANFIS and MLR predictions are slightly overestimated as the margin between $A B E$ is very close to zero. On the other hand, the ABE estimated for $\mathrm{H}$ using the ANFIS, MLR, and Nhuchhen (2016) models are positive while that of others is negative hence ANFIS, MLR and Nhuchhen (2016) models slightly overestimate the value of $\mathrm{H}$ but Nhuchhen (2016) model deviates more from the experimental predictions. In addition, $\mathrm{ABE}$ for the $\mathrm{O}$ shows that four of the models overestimate the oxygen content of the fuels though the deviation of the MLR model from the experimental model is very small while two of the models slightly underestimate the oxygen content. It can be inferred from the error analysis performed that the ANFIS models have the least error follow by ANN and then MLR. Similarly, Shen et al. (2010) model has the highest error values follow by Parikh et al. (2007) model and then Nhuchhen (2016) model. Hence, the performance of the proposed models is promising.

\subsection{Sensitivity analysis}

Sensitivity analysis is a technique used to evaluate the input parameters that most affect the output parameters. Jong and Lee (2004) reported that the cosine amplitude approach can be employed to evaluate sensitivity analysis. The cosine amplitude method is as illustrated in Eq. (29).

$r_{i j}=\frac{\sum_{i=1}^{n}\left(I_{i} \times O_{t i}\right)}{\sqrt{\sum_{i=1}^{n} I_{i}^{2} \sum_{i=1}^{n} O_{t i}^{2}}}$

where $I_{i}$ and $O_{t j}$ represent the input and output parameters, and $n$ is the number of sample data points.
The cosine amplitude method has also been used by various researchers in the field of geotechnical engineering. For instance, Monjezi et al. (2012) studied the influence of various parameters on the uniaxial compressive strength of the rock. Momeni et al. (2014) determined the parameters influencing the bearing capacity of stockpile using the cosine amplitude approach. However, none of the existing studies for predicting the elemental composition of solid fuel conducted the sensitivity analysis using the CAM. Hence, in this study, a sensitivity analysis was conducted using the outputs from the three methods used and the order of the importance of the independent variables is as presented in Fig. 11. The results presented in Fig. 11 based on the cosine amplitude approach in Eq. (29) show the strength of the relation between the input and output parameters for the three models developed. For the case of $\mathrm{C}$ (Fig. 11a), FC content has the highest influence on it as expected follow by VM. A and M contents have a similar impact on C. On the other hand, VM has the highest influence on both $\mathrm{H}$ and $\mathrm{O}$ (Figs. 11b and c) follow by $\mathrm{M}$, FC and then A contents for the three models proposed in this study.

\section{Conclusions}

It is difficult to evaluate the elemental composition of coal and biomass through laboratory tests as the test is timeconsuming and costly. As a result of the difficulty, the elemental composition of coal and biomass cannot sometimes be obtained by laboratory tests, especially when considering small to medium-size engineering projects. In the first part of the study, in order to overcome this limitation, prediction models were developed by using proximate and elemental analyses data obtained from the laboratory tests, and ANFIS, ANN and MLR as the prediction tools. The prediction models developed have strong prediction capacities and can be used to estimate the elemental composition of coal and biomass.

In the second part of the study, the developed prediction models were compared with some existing empirical equations for estimating the elemental composition of similar materials. For all the parameters of elemental composition (i.e. carbon, hydrogen, and oxygen) investigated, the proposed models have a higher coefficient of correlations than the existing models. In addition, error analyses were performed to further compare the performances of the proposed models with those of the existing models in the literature using MAE, AAE, and $\mathrm{ABE}$ as prediction error indicators. For the three elements of coal and biomass investigated, the models developed in this study have the smallest values of MAE, AAE, and ABE except for carbon and hydrogen where there are 
overlapping of performances in ABE estimates. This shows that using prediction models established in this study leads to smaller errors compared to the existing models.

While comparing the ANFIS, ANN and MLR models proposed in this study, it is obvious that the ANFIS models have higher predictive capacities than the ANN models and, lastly, are followed by the MLR models. This may be mainly due to non-linearity between independent and dependent variables. However, the performances of the proposed models are satisfactory and they can be used for practical purposes.

Open Access This article is licensed under a Creative Commons Attribution 4.0 International License, which permits use, sharing, adaptation, distribution and reproduction in any medium or format, as long as you give appropriate credit to the original author(s) and the source, provide a link to the Creative Commons licence, and indicate if changes were made. The images or other third party material in this article are included in the article's Creative Commons licence, unless indicated otherwise in a credit line to the material. If material is not included in the article's Creative Commons licence and your intended use is not permitted by statutory regulation or exceeds the permitted use, you will need to obtain permission directly from the copyright holder. To view a copy of this licence, visit http://creativecommons. org/licenses/by/4.0/.

\section{References}

ASTM D5373-14:2015. Standard test methods for determination of carbon, hydrogen and nitrogen in analysis samples of coal and carbon in analysis samples of coal and coke

ASTM, D5142. Standard test methods for proximate analysis of the analysis sample of coal and coke by instrumental procedures

Bahrami A, Monjezi M, Goshtasbi K, Ghazvinian A (2011) Prediction of rock fragmentation due to blasting using artificial neural network. Eng Comput 27(2):177-181

Channiwala SA, ParikhP P (2002) A unified correlation for estimating HHV of solid, liquid and gaseous fuels. Fuel 81:1051-1063

Chelgani SC, Hower JC, Jorjani E, Mesroghli S, Bagherieh A (2008) Prediction of coal grindability based on petrography, proximate and ultimate analysis using multiple regression and artificial neural network models. Fuel Process Technol 89:13-20

Chen W, Peng J, Bi X (2015) A state-of-the-art review of biomass torrefation, densification and applications. Renew Sustain Energy Rev 44:847-866

Dehghani H, Ataee-pour M (2011) Development of a model to predict peak particle velocity in a blasting operation. Int J Rock Mech Min Sci 48(1):51-58

Dreyfus G (2005) Neural networks: methodology and application, 2nd edn. Springer, Berlin

Du KL, Lai AKY, Cheng KKM, Swamy MNS (2002) Neural methods for antenna array signal processing: a review. Signal Process 82:547-561

Fausett LV (1994) Fundamentals of neural networks: architecture, algorithms and applications. Prentice-Hall, Englewood Cliffs

Gokceoglu C, Zorlu K (2004) A fuzzy model to predict the uniaxial compressive strength and the modulus of elasticity of a problematic rock. Eng Appl Artif Intell 17:61-72

Habibagahi G (2002) Post-construction settlement of rockfill dams analyzed via adaptive network-based fuzzy inference systems. Comput Geotech 29:211-233
Haseli Y (2018) Process modeling of a biomass torrefaction plant. Energy Fuels 32:5611-5622

Haykin S (1999) Neural networks, 2nd edn. Prentice-Hall, Englewood Cliffs

IEA (2018) Power generation from coal: ongoing development \& outlook. Information paper. OECD/IEA, Paris, p 49

Iphar M (2012) ANN and ANFIS performance predcition models for hydraulic impact hammers. Tunn Underg Space Technol 27:23-29

Jahed AD, Tonnizam ME, Momeni E, Narayanasamy MS, Mohd MA (2014) An adaptive neuro-fuzzy inference system for predicting unconfined compressive strength and Young's modulus: a study on main range granite. Bull Eng Geol Env. https://doi.org/10. 1007/s10064-014-0687-4

Jang RJ (1993) ANFIS: adaptive-network-based fuzzy inference system. IEEE Trans Syst Man Cybern 23:665-685

Jang JSR, Gulley N (1995) The fuzzy logic toolbox for use with MATLAB. The Mathworks Inc, Natick

Jang JSR, Sun CT, Mizutani E (1997) Neuro-fuzzy and soft computing, a computational approach to learning and machine intelligence, 1st edn. Prentice Hall, New Jersey

Jong YH, Lee CI (2004) Influence of geological conditions on the powder factor for tunnel blasting. Int J Rock Mech Min 41:533-538

Kalinli A, Acar MC, Gunduz Z (2011) New approaches to determine the ultimate bearing capacity of shallow foundations based on artificial neural networks and ant colony optimization. Eng Geol 117:29-38

Komilis D, Evangelou A, Giannakis G, Lymperis C (2012) Revisiting the elemental composition and the calorific value of the organic fraction of municipal solid wastes. Waste Manag 32:372-381

Loukas YL (2001) Adaptive neuro-fuzzy inference system: an instant and architecture-free predictor for improved QSAR studies. J Med Chem 44:2772-2783

Mathews JP, Krishnamoorthy V, Louw E, Tchapda AH, CastroMarcano F, Karri V (2014) A review of the correlations of coal properties with elemental composition. Fuel Process Technol 121:104-113

Mohr SH, Wang J, Ellem G, Ward J, Giurco D (2015) Projection of world fossil fuels by country. Fuel 141:120-135

Momeni E, Nazir R, Jahed AD, Maizir H (2014) Prediction of pile bearing capacity using a hybrid genetic algorithm-based ANN. Measurement 57:122-131

Monjezi M, Khoshalan HA, Razifard M (2012) A neuro-genetic network for predicting uniaxial compressive strength of rocks. J Geotech Geoenviron Eng 30(4):1053-1062

Monjezi M, Hasanipanah M, Khandelwal M (2013) Evaluation and prediction of blast-induced ground vibration at Shur River Dam, Iran, by artificial neural network. Neural Comput Appl 22:1637-1643

Nhuchhen DR (2016) Prediction of carbon, hydrogen, and oxygen compositions of raw and torrefied biomass using proximate analysis. Fuel 180:348-356

Onifade M (2018) Spontaneous combustion liability of coals and coal-shales in the South African coalfields. A PhD Thesis, University of the Witwatersrand, Johannesburg, South Africa

Onifade M, Genc B (2018) Prediction of the spontaneous combustion liability of coal and coal-shale using statistical analysis. J S Afr Inst Min Metall 118:799-808

Onifade M, Lawal AI, Aladejare EA, Bada S, Idris MA (2019) Prediction of gross calorific value of solid fuels from their proximate analysis using soft computing and regression analysis. Int J Coal Prep Util. https://doi.org/10.1080/19392699.2019. 1695605 
Parikh J, Channiwala SA, Ghosal GK (2007) A correlation for calculating elemental composition from proximate analysis of biomass materials. Fuel 86:1710-1719

Rafiei-Sardooi E, Mohseni-Saravi M, Barkholi S, Azareh A, Choubin B, Jafari-Shalamzar M (2018) Drought modelling: a comparative study between time series and neuro-fuzzy approaches. Arab J Geosci 11:487

Rumelhart DE, Hinton GE, Williams RJ (1986) Learning internal representation by error propagation. In: Rumelhart DE, McClelland L (eds) Parallel distributed processing. MIT Press, Cambridge

Sahu HB, Mahapatra SS (2013) Forecasting spontaneous heating susceptibility of Indian coals using neuro fuzzy system. Geotech Geol Eng 31:683-697

Sahu MM, Mahapatra SS, Sahu HB (2011) Prediction of water quality index using neuro fuzzy inference system. Water Qual Expo Health 3:175-191

Seifi A, Riahi H (2018) Estimating daily reference evapotranspiration using hybrid gamma test-least squuare support vector machine, gamma test-ANN, and gamma test-ANFIS models in an arid area of Iran. J Water Clim Change. https://doi.org/10.2166/wcc.2018. 003

Shafiee S, Topal E (2009) When will fossil fuel reserves be diminished? Energy Policy 37:181-189

Shahin MA, Maier HR, Jaksa MB (2002) Predicting settlement of shallow foundations using neural networks. J Geotech Geoenviron Eng 128:785-793

Shen J, Zhu S, Liu X, Zhang H, Tan J (2010) The prediction of elemental composition of biomass based on proximate analysis. Energy Convers Manag 51:983-987

Simpson PK (1990) Artificial neural system: foundation, paradigms, applications and implementations. Pergamon, New York, p 209

Vakkilainen EK (2000) Estimation of elemental composition from proximate analysis of black liquor. Paperi ja puu-Paper Timber 82(7):450-454

Van der Stelt MJC, Gerhauser H, Kiel JHA, Ptasinski KJ (2011) Biomass upgrading by torrefaction for the production of biofuel: a review. Biomass Bioenergy 35:3748-3762 